\title{
Common Features in Local Employees' Behavior concerning Information Security Management in Foreign Companies
}

\author{
Suchinthi Fernando (Corresponding author) \\ Information Science \& Control Engineering, Nagaoka University of Technology \\ 1603-1 Kamitomioka-machi, Nagaoka, Niigata, 940-2188 Japan \\ Tel: 81-90-3099-2350Ｅ-mail: s095191@nagaokaut.ac.jp \\ Tatsuo Asai \\ Professor Emeritus, Nagaoka University of Technology \\ Visiting Researcher, Institute of Information Security \\ 2-14-1 Tsuruya-cho, Kanagawa-ku, Yokohama, 221-0835 Japan \\ Tel: 81-45-410-0222 E-mail: asaitats@gmail.com \\ Takashi Yukawa \\ Electrical Engineering / Information \& Telecommunication Systems Group \\ Nagaoka University of Technology \\ 1603-1 Kamitomioka-machi, Nagaoka, Niigata, 940-2188 Japan \\ E-mail: yukawa@vos.nagaokaut.ac.jp
}

Received: August 15, 2012

Accepted: September 1, 2012

Online Published: September 6, 2012

doi:10.5430/bmr.v1n3p95

URL: http://dx.doi.org/10.5430/bmr.v1n3p95

\begin{abstract}
Purpose - This paper examines common features in local employees' behavior leading to problems in information security in foreign companies due to cultural differences between foreign managers and local workers.

Design/methodology/approach - The investee countries of Russia, India, China, Brazil, Thailand, Venezuela, Malaysia and the East African Community are examined. Potential human-related problems developed using Hofstede's framework of culture and the results of previously conducted studies are examined and their linkage to cultural dimensions are validated using human behavioral heuristics.

Findings - The problems of "Unintentional sharing of confidential information" and "Concealing faults made by friends" occur because of lower individualism of investee countries, while the problem of "Using any means to reach goals owing to high competition" occurs because of higher masculinity of the society.

Originality/value - This paper has identified that human-related information security problems are linked to the investee countries' cultural dimensions through the behavioral patterns influenced by their cultures.
\end{abstract}

Keywords: Information Security Management, Human-related problem, Cultural difference, Cultural dimension, Behavior

\section{Introduction}

Diversity within an organization allows it to effectively cope with unexpected circumstances. Thus, most companies, including local domestic ones, nurture cross-cultural business environments. Despite the many benefits available through diversity, cultural differences between foreign managers and local workers could lead to many misinterpretations and misunderstandings resulting in various problems including Information Security Management (ISM) problems. Internal Control - Integrated Framework of Committee of Sponsoring Organizations (1994) refers to Foreign Operations in Circumstances Demanding Special Attention in Managing Change, where it states that: "The expansion or acquisition of foreign operations carries new and often unique risks that management should 
address. For instance, the control environment is likely to be driven by the culture and customs of local management." This framework refers to corporate culture, whereas this study concerns national culture, which may influence the former.

Despite having revolved around technological aspects in the early days, information security is no longer considered a purely technological matter. Asai (2007) has pointed out the importance of taking human resource security into consideration. This shift from being "technology-oriented" to "management-oriented" is defined by Lacey (2009) as "the shifting focus of information security." The Committee of Sponsoring Organizations (COSO) framework (1994) and the International Standards Organization's official standard for information security, ISO/IEC 27001 (2005), also emphasize the importance of taking the human factor into account when managing information security. Bean (2008) states that most identified information security breaches today, occur because of human errors resulting from lack of proper knowledge and training, ignorance and failure to follow procedures. Schneier (2008) explains how the perception of security diverges from its reality and how people feel secure as long as there is no visible threat. This human weakness is exploited in most present-day attacks, which require a human element to be completed successfully (Williams, 2011). These attacks may come in the forms of social engineering, spear phishing or collusion from an insider, where people are tricked into revealing confidential information to others. Thus, in order to succeed in business, it is mandatory to ensure that access to information is strictly limited to the personnel who need to know it in order to perform their assigned tasks (Schweitzer, 1996). People's beliefs and expectations may lead to mistakes and misjudgments of risks (Pronin, 2006). Through his framework of Cultural Dimensions (CDs), Hofstede (2004) shows how people's beliefs and expectations are influenced by their culture, where people from different cultures react to similar situations in different ways. Hence, it can be inferred that mismatches in cultures between management and employees could lead to unintentional security breaches.

Studies concerning the impact of culture on ISM in cross-cultural environments were limited until the Information Systems Planning Laboratory of the Nagaoka University of Technology conducted a series of studies to find ISM problems faced by foreign companies in investee countries. These studies were conducted in attractive destinations for Foreign Direct Investment (FDI) such as Russia (RU), India (IN), China (CN), Brazil (BR), Thailand (TH), Venezuela (VN), Malaysia (MA) and the East African Community (EA). The problems faced by the top investor countries of these investee countries were predicted using the theory of Level of Potential $(L o P)$ developed by Asai and Waluyan (2008). This theory proves that the likelihood of occurrence of problems is correlated to the magnitude of difference of CDs between an investor country and an investee country (Waluyan et al., 2010).

This study aims to validate the linkage between CDs and potential ISM problems by examining the impact of national culture on human behavior, which leads to ISM problems in foreign companies.

\section{Cultural Impact on Human Behavior}

\subsection{Cultural aspects}

Extensive theories explaining the cultural implications on human behavior have been presented by Hofstede (2004), Hall (1976), Trompenaars (Straker, 2002) and House et al. (2004). Of these, Hofstede's framework of Cultural Dimensions, which concerns how culture influences workplace values, is used in these studies to predict potential problems in cross-cultural business environments.

The scores for CDs assigned by Hofstede are based on a comprehensive global survey and have withstood many criticisms. Despite the concerns of assigning rigid scores to multi-ethnic nations and divergence of nations from these scores over time, Hofstede's scores are still being widely used in many areas of research. These CDs, summarized by Yates (2006), are presented in Table 1.

Table 2 presents Hofstede's scores for each of the investee countries in these previously conducted studies. These scores have been classified into 5 degrees by Asai and Waluyan (2008), namely: very low, low, moderate, high and very high by equally dividing the range of scores between the highest and the lowest scores for a CD among all the countries surveyed by Hofstede. Figure 1 represents Hofstede's cultural scores for each of these countries graphically, while Table 3 depicts the correlation matrix of cultural scores among them. As shown by Figure 1 and the groupings of Tables 2, the CDs of Power Distance Index (PDI), Individualism (IDV) and Masculinity (MAS) tend to follow a similar pattern among all of the investee countries, with PDI ranging from moderate to very high, IDV from very low to moderate and MAS from Low to High. These also show that, apart from China, which has the highest score for Long Term Orientation (LTO), all other countries have LTO scores ranging from low to moderate. No LTO scores are given for Russia, Venezuela or Malaysia. This indicates that the cultures of investee countries are usually such that their societies accept the unequal distribution of power, they tend to work in groups valuing friendship and they 
are competitive. It can also be seen from Table 3 that the cultures of Russia, Brazil and Thailand are very close to each other, while the Indian culture is very similar to that of Malaysia. The Chinese culture is also somewhat close to that of Malaysia, while Russia and Venezuela are somewhat culturally close to East Africa. Venezuela is also culturally close to Brazil and Thailand. Overall, it can be stated that, with the exception of China and East Africa, most investee countries are, in general, culturally close to each other. Thus, it is safe to assume that most common problems faced by foreign managers in these countries occur because of the common behavioral patterns resulting from the cultural backgrounds of these investee countries.

In order to explore this assumption in depth, a closer look at cultural effects on human behavior is required. Section 2.2 looks at behavioral aspects in order to do so.

\subsection{Behavioral aspects}

Elsaid and Elsaid (2012) state that an adequate understanding of a human's behavior requires examination both in terms of a general and a specific structural context across cultures.

According to the American Association for the Advancement of Science (AAAS), humans are a species living in the company of other humans, organized into social groupings. Social scientists study human behavior from cultural, political, economic and psychological perspectives, looking for consistent patterns of individual and social behavior and scientific explanations of those patterns. Human behavior is affected by both genetic inheritance and experience. The characteristics of the social and cultural setting, such as family, community, social class, language and religion a person is born into, affect how he thinks and behaves. In addition to the means of instruction, example, and rewards and punishment, one's thoughts and behavior are also influenced by informal interactions with friends, peers, relatives and media. There is substantial similarity in responses to the same pattern of influences by individuals being raised in the same culture. Social distinctions of a person's culture influence his perception of the social world. Acceptable human behavior varies from culture to culture and from time to time. Unusual behavior could be considered amusing, distasteful or punishable. For instance, aggressively competitive behavior is considered rude in highly cooperative cultures, while lack of competition is regarded lazy in others. Technology has always played a major role in human behavior, leading to rapid spread of fashions and ideas through international travel and mass media, and implicitly promoting values, aspirations, priorities and attitudes. Thus, nations and cultures are now increasingly dependent on one another through international economic systems and shared environmental problems (AAAS, 1990). The cultural gaps created between local employees and foreign managers in cross-cultural business environments in turn lead to work-related problems, including ISM problems, resulting from the differences in behavioral patterns in these different cultures and societies.

O'Neil (2006) states that culture primarily relates to the way people interact with each other. Anthropologists and observant visitors find that the ideal behavior of extreme masculinity or extreme femininity in Latin America, or the cultural ideals for gender roles in rural South China, where they believe "the husband to be the outside master, while the wife is the inside master", are difficult to live up to. O'Neil also states that a person living in another society that is culturally very different is likely to initially develop culture shock, emotionally debilitating confusion, distress and depression resulting from psychological stress during the first few weeks of a total cultural immersion in an alien society. Over time, as a realistic understanding of the cultural patterns in a society is developed, the cultural distance is reduced (O'Neil, 2006). This further emphasizes the fact that a foreign manager would be able to avoid problems resulting from cultural gap between oneself and the local employees if he learns the local culture and understands the employees' behavioral patterns.

Cisco Systems, Inc. commissioned a research study named "Data Leakage Worldwide" in 2008 to explore how geographical and cultural differences influence information security behaviors of 2020 information technology (IT) users and decision makers in Australia, Brazil, China, France, Germany, India, Italy, Japan, the United Kingdom and the United States. Hayden (2009) summarizes the findings of this study. These findings include differences in perception of information security, incorporation of security into daily practices, and effectiveness of organizational policies designed to promote and enforce security behaviors, across different countries. This study includes human information behaviors across cultural and regional boundaries, and thus, supports our assumption. Hayden (2009) shows that many researches had been conducted concerning how country differences influence information seeking behaviors of global finance firms, information behaviors of indigenous people in developing countries, information behaviors of online consumers in the United States and Hong Kong, etc. Assignation of determined protection to information resources is influenced by state, organizational and individual decisions, and activities. Brice (2012) discusses how some dimensions of ethnic cultures concerning managerial attitudes and practices are affected by national culture. Würtz (2005) discusses different information communication behaviors across different cultures, 
when she "explores strategies used by High-Context cultures in utilizing the Internet, a largely Low-Context medium, for communication and marketing purposes." Low-Context cultures, such as those of Scandinavians, Germans and the Swiss, communicate through explicit statements in text and speech, whereas High-Context cultures, such as those of Japanese and Chinese, use other communicative cues including body language, gestures, proximity, and silence, implying messages through what is not uttered. These studies further emphasize the importance of understanding these cultural characteristics when managing employees from different cultures.

West (2008) explains how risk and uncertainty are difficult concepts for people to evaluate. "Fundamentally, the user problem in security systems is about how people think of risks that guide their behavior... Basic principles of human behavior that govern how users think about security in everyday situations show why they undermine security accidents." Predictable and exploitable characteristics in the human decision-making process include belief that they are at less risk, risk homeostasis (maintaining an acceptable degree of risk and increasing risky behavior to suit increased security measures), cognitive miserliness (having a limited capacity for information processing and multitasking) leading to quick, uninformed decisions based on learned rules and heuristics, feeling less motivated by abstract concepts like security, incorrect evaluations of trade-off between security and cost, and perceiving loss disproportionately to gains. West (2008) concludes that for many people, security becomes a priority only when they have problems with it. This study clarifies why people from different cultures react in different ways concerning information security.

Bruce Schneier (2008) conducts a closer examination of these heuristics. He states that "security is both a feeling and a reality." While the reality is mathematical, based on probability of different risks and effectiveness of different countermeasures, the feeling is based on one's psychological reactions to risks and countermeasures. One can be secure without feeling secure and vice versa. Schneier (2008) attempts to find why this feeling of security diverges from the reality by researching about behavioral economics (emotional, social and cognitive human biases), psychology of decision-making and bounded rationality, psychology of risk and risk perception, and neuroscience (how human brains have developed complex mechanisms to deal with threats). Any gain in security involves trade-offs in terms of money, time, convenience, capabilities or liberties. Humans make trade-offs intuitively, exaggerating some risks or costs, while downplaying others. Aspects of trade-off such as the severity of the risk, probability of the risk, magnitude of the costs, effectiveness of countermeasures at mitigating the risk, and comparison of disparate risks and costs, can go wrong. The more the perception diverges from reality, the more the perceived trade-off diverges from the actual trade-off. Reasons for incorrect perception of risks are listed in Table 4.

Human risk-perception fails because new situations have occurred at a faster rate than human evolution (Schneier, 2008). The "amygdala", a primitive part of the brain, processes base emotions from sensory inputs, like anger, avoidance, defensiveness, and fear, triggering the fight-or-flight response. Yet, some situations are better handled by sophisticated analysis of situation and options using the "neocortex", a recently developed part of the brain in mammals. Having two systems operating in parallel makes people feel both rational and flighty at the same time. Unfortunately, this newer innovation of the brain is still in its early stages of development, resulting in many miscalculations. Instead of evaluating security trade-offs mathematically, humans use shortcuts, rules of thumb, stereotypes, and biases, known as heuristics, to generate answers quickly, with limited cognitive capabilities. Schneier (2008) explains these heuristics and theories through many scientifically conducted experiments. These behavioral heuristics, which may affect the way people react to ISM-related problems, are summarized in the following section.

\subsection{Behavioral heuristics}

The heuristics governing human behavior as explained by Schneier (2008) are summarized here. These heuristics are used in section 5 in order to examine the linkage between the cultures of investee countries examined in section 2.1 and the survey results concerning information security problems in these countries presented in section 4 .

\subsubsection{Risk heuristics}

- Prospect Theory - Kahneman and Tversky (1979) state that humans accept small sure gains rather than risking/chancing a larger gain, and risk/chance larger losses rather than accepting smaller sure losses

- Endowment Effect - humans value something more when represented as something that can be lost, as opposed to a potential gain, as shown in Figure 2

- Optimism Bias and Control Bias - humans believe that good outcomes are more probable than bad outcomes, and are more likely to accept risks they feel they have some control over 
- Affect Heuristic - an overall good feeling toward a situation leads to a lower risk perception, while an overall bad feeling leads to a higher risk perception

2.3.2 Probability heuristics

- Small numbers matter more than large numbers (a half, a quarter, one eighth, or almost nothing)

- Availability Heuristic and Hindsight Bias - humans consider something that is more available to be more probable (common events, vivid and salient arguments) and consider events that have actually occurred previously to be more probable

- Representativeness and Law of Small Numbers - humans assume that the probability that an example belongs to a particular class is based on how closely that example represents the class, and that long-term probabilities also hold true in the short run

\subsubsection{Cost heuristics}

- Mental Accounting - humans have different mental budgets and may be willing to accept considerable risks in one mental account, but would not consider them if charged against a different account

- Time Discounting - humans tend to discount future costs and benefits

- Magnitude Effect - smaller amounts are discounted more than larger ones

- Framing Effect - framing something as an acceleration or a delay from a base reference point

2.3.4 Decision heuristics

- Context Effect - humans tend to choose options that dominate other options, or compromise options that lie between other options (avoiding extremes)

- Choice Bracketing - humans choose a more diverse set of items when the decision is bracketed more broadly than when bracketed more narrowly

- Anchoring Effect - human decisions are affected by random information cognitively nearby (mentally adjusting facts to suit facts anchored in their minds)

- Confirmation Bias - humans are more likely to notice evidence supporting a previously held position rather than evidence that discredits it

\section{Research Method}

\subsection{Assumption}

It is assumed that most problems which impede the effective implementation of security policies in cross-cultural environments occur because of the differences in culture between foreign managers and local workers, which lead to different behavioral aspects resulting in different opinions and misunderstandings. If, however, foreign managers try to learn and understand the local culture which shapes the behavior of local workers, then the manager would be in a better position to try to fill this mind gap, and therefore, successfully protect the company's business information.

\subsection{Cultural aspects leading to ISM problems}

It is hypothesized in this study that aspects of cultural dimensions of local employees working for foreign companies lead to behavior resulting in human-related ISM problems. Equations 1 through 4 formulate these hypotheses.

H1: Lower IDV leads to "Unintentional sharing of confidential information"

H2: Lower IDV leads to "Concealing faults made by friends"

H3: Higher MAS leads to "Using any means to reach goals owing to high competition"

H4: Lower LTO leads to "Using previous company's confidential information"

This research uses the results obtained through previously conducted studies to find human-related ISM problems in cross-cultural environments to test the above hypotheses to find the likelihood of the linkage between CDs and ISM problems.

\subsection{Approach}

Practical potential problems were developed by the authors of the series of studies conducted concerning human-related ISM problems in cross-cultural environments in Russia, India, China, Brazil, Thailand, Venezuela, Malaysia and the East African Community, based on CDs of these investee countries and prior business experience. 
The potential problems predicted in these studies, along with the results of the surveys conducted, are utilized here in order to validate the linkage between CDs and these predicted problems. The steps listed below are followed in this study:

(1) Obtain lists of potential problems predicted in investee countries and the results of analyses of survey results in previously conducted studies.

(2) Compare the likelihood of occurrence of these potential problems against the CDs of investee countries.

(3) Analyze the common features in local employees' behavior concerning ISM in foreign companies through human behavioral heuristics.

(4) Recommend countermeasures to cope with identified problematic behavior and thereby prevent the occurrence of problems.

\section{Common ISM problems found through previous studies}

In order to find out common behavioral patterns among local employees working for foreign companies, it is necessary to find the common ISM problems found to be serious in investee countries. This section summarizes the results of the findings of the series of studies conducted by the Information Systems Planning Laboratory of Nagaoka University of Technology. The studies concerning Russia (Asai, Fernando and Castillo, 2011), India (Asai and Fernando, 2011), China (Asai, Yun and Caibutengdaoriji, 2011), Brazil (Waluyan et al., 2010), Thailand (Siripukdee et al., 2010), Venezuela (Castillo et al., 2009), Malaysia (Waluyan et al., 2009) and East Africa (Asai and Hakizabera, 2010) were carried out during the time span of 2008 through 2010 through Internet-based surveys. The entire lists of potential problems, lists of questions composed of conditions triggering the problems, survey profiles, summarized survey results and detailed analyses of results of these surveys are available in the above references. The overall profile of respondents (Asai, 2011 a, and Asai, 2011 b) is summarized in Table 5.

According to the results of the series of studies mentioned in section 3.3, a problem was found to be serious if more than $50 \%$ of the respondents gave answers which lead to the occurrence of problems. Table 6 lists the common problems found to be serious in each of these countries and the CDs under which they are categorized. " $\sqrt{ }$ " denotes serious problems, while "-" indicates that the problem is not listed for that particular country. From this table it can be seen that the problems of "Unintentional sharing of confidential information", "Concealing faults made by friends", "Using any means to reach goals owing to high competition" and "Using previous company's confidential information" are common to 4 or more of these countries. The problems categorized under PDI and Uncertainty Avoidance Index (UAI) are not common to 4 or more countries and thus, are not discussed in this paper. The next section will validate the linkage between these common problems and CDs by examining human behavioral patterns of these cultures that could lead to these problems.

\section{Linkage between problems and cultural dimensions}

This section will examine the heuristics presented by Schneier (2008) in order to explain different behaviors in different cultures considered in this study.

Table 6 showed that of the serious problems common to most countries, "Unintentional sharing of confidential information" is serious in Russia, India, China, Brazil, Thailand, Malaysia and the East African Community, and that "Concealing faults made by friends" is serious in Russia, India, China and Thailand. Table 2 shows that all these countries have very low through moderate scores for IDV. In a collectivist society with lower individualism, people would naturally place great importance on friendship and groups. According to optimism bias, people do not think that bad outcomes are very likely, and through time discounting, they discount problems that will occur in the future and instead focus on immediate benefits, when they unintentionally share confidential information with others. Confirmation bias will lead a person to believe that their friends will never use this information in a way that could jeopardize that person, further strengthening his act. In accord with prospect theory and endowment effect, a person would rather keep his friend by concealing the friend's mistakes rather than risk losing him by reporting his mistake. Anchoring effect and confirmation bias will further help a person to believe that his friend will not do something that is truly wrong or harmful. Thus, these heuristics prove the following two hypotheses concerning these two problems in collectivist societies:

\section{H1: Lower IDV leads to "Unintentional sharing of confidential information" \\ H2: Lower IDV leads to "Concealing faults made by friends"}

Table 6 also showed that "Using any means to reach goals owing to high competition" is serious in India, China, Brazil, Venezuela, Malaysia and the East African Community. From Table 2 we can see that all these countries have 
moderate through high scores for MAS. In a society with higher masculinity, people tend to be highly assertive and competitive. Prospect theory and endowment effect make people believe that the benefits of achieving their goals are much higher than the losses incurred if these goals were not somehow achieved. Further, optimism bias and affect heuristic give them a good feeling about working hard to reach their goals, while the control bias and context effect ensures them that all risks taken are within their control. In addition, confirmation bias will further confirm to them that reaching high goals give high benefits, particularly if they are appraised based on their performance. Thus, people in higher masculinity societies will be blinded to the harms of losses incurred during their quest by their need to reach goals, proving the following hypothesis concerning this problem:

H3: Higher MAS leads to "Using any means to reach goals owing to high competition"

Finally, Table 6 showed that "Using previous company's confidential information" is serious in India, China, Brazil, Thailand and the East African Community. Table 2 shows that, with the exception of China, all of these countries have low through moderate scores for LTO. Lower long-term orientation leads people to be blinded to long-term losses by short-term benefits. Prospect theory shows that a person would rather use knowhow obtained from previous companies and benefit at present rather than not use it, since he believes he has nothing to lose. Control bias also gives them control over this risk. Time discounting plays an exemplary role in short-term oriented societies to discount future losses for immediate gain, thus supporting the final hypothesis concerning this problem:

\section{H4: Lower LTO leads to "Using previous company's confidential information"}

Yet, China, being the country with the highest score for LTO, is an exception. Chinese employees who prefer to maintain long-term good relations with their managers may offer intellectual gifts, resulting in this problem which is also serious in China. There is not, however, enough data to verify this interpretation. Thus, this will be an interesting topic for future investigation.

\section{Recommendations}

From this study, we have found that lower IDV scores of investee countries lead to the problems of "Unintentional sharing of confidential information" and "Concealing faults made by friends". Thus, it is recommended to foreign managers to understand the local workers' cultures, which lead them to work in groups valuing friendship highly. This allows managers to educate their employees about the principle of need-to-know, that only a person who truly needs to know a certain piece of information in order to perform his tasks should be allowed access to that information, and to encourage reporting of faults made by friends, as reporting of faults would not result in employees or their friends being reprimanded, but instead help their companies in correcting these mistakes and in surviving in business.

Since the problem of "Using any means to reach goals owing to high competition" occurs because of higher scores for MAS, it is recommended to foreign managers to help their employees to understand that competitiveness should not be at the risk of security and that practices such as taking office documents home without official permission concerning information security should be avoided since such practices could lead to exposure of confidential business information.

As either lower LTO scores or very high LTO scores lead to the problem of "Using previous company's confidential information", foreign managers are recommended to teach their employees that knowhow acquired while working for a company is that company's asset, even though the employees' acquired skills are their assets, and that it is illegal to use a company's information for other purposes to obtain personal benefits. ISO/IEC 27001 (2005) also points out the importance of using non-disclosure agreements to bond employees to secrecy regarding confidential information.

\section{Conclusions and future work}

Based on the testing of hypotheses that human-related ISM problems in foreign companies are linked to the culture of local employees through their behavioral patterns, it can be concluded that potential ISM problems are linked to cultural dimensions of the investee country:

(1) Lower individualism of investee country leads to "Unintentional sharing of confidential information"

(2) Lower individualism of investee country leads to "Concealing faults made by friends"

(3) Higher masculinity of society leads to "Using any means to reach goals owing to high competition"

It should, however, be noted that using these results in future may not give $100 \%$ accuracy due to adaptation of employees to the corporate cultures of their organization in time and thus, deviating from their national culture. 
The human behavioral characteristics leading to the problem of "Using previous company's confidential information" may occur from either lower long-term orientation of investee countries, where employees pursue short-term benefits, or from very high long-term orientation of Chinese employees who prefer to maintain long-term good relations with their managers. This interpretation could not be verified because of the lack of data. Thus, this topic is recommended as a topic for future investigation.

\section{References}

American Association for the Advancement of Science (1990). Chapter 7: Human society. [Online] Available: http://www.project2061.org/publications/sfaa/online/chap7.htm (November 22, 2011).

Asai,T. (2011)a. The Influence of Religion and Gender on Information Security Problems in Cross-Cultural Environments. Proceedings of the Fifth International Symposium on Human Aspects of Information Security \& Assurance HAISA 2011, 130-141.

Asai, T. (2011)b. A Proposal of New Cultural Measures Based on Hofstede's Cultural Dimensions - Cultural Similarity, Conformity and Flexibility -, Proceedings of the 46th National Conference of Japan Association for Management Systems, 158-161.

Asai, T. (2007). Information Security and Business Activities. Niigata, Japan: Kameda Book Service.

Asai, T. and Fernando, S. (2011). Human-related problems in information security in Indian cross-cultural environments. Journal of Japan Society of Security Management, 25(2), 3-14.

Asai, T., Fernando, S. and Castillo, J. (2011). Human-related problems in information security in Russian cross-cultural environments. International Journal of Japan Association for Management Systems, 3(1), 31-40.

Asai, T. and Hakizabera, A.U. (2010). Human-related problems in information security in East African cross-cultural environments. Journal of Information Management \& Computer Security, 18(5), 328-338. http://dx.doi.org/10.1108/09685221011095245

Asai. T., Qin, Y. and Caibutengdaoriji (2012). The influence of cultural differences on information security management in Chinese cross-cultural working environments. Journal of Japan Association for Management Systems, 28(1), 25-33.

Asai, T. \& Waluyan, L. (2008). Potential problems in information security management in cross-cultural environment - a study of cases in Indonesia -. Journal of Japan Society of Security Management, 21(3), 15-26.

Bean, M. (2008). Human Error at the Center of IT Security Breaches. [Online] Available: http://www.newhorizons.com/elevate/network\%20defense\%20contributed\%20article.pdf (February 10, 2008).

Brice, W. D. (2012). The effects of ethnic culture on managerial attitudes and practices: a survey in Hong Kong, Taiwan and China. International Journal of Management, 29(1), 267-278.

Castillo, J., Waluyan, L. and Asai T. (2009). Analysis of potential problems in people management concerning information security in cross-cultural environment - A study concerning foreign companies including Japanese companies in Venezuela -. Journal of Japan Society of Security Management, 25(2), 13-19.

Committee of Sponsoring Organizations (1994). Internal Control - Integrated Framework. [Online] Available: http://www.snai.edu/cn/service/library/book/0-Framework-final.pdf (February 17, 2008).

Elsaid, E. and Elsaid, A. M. (2012). Culture and leadership: comparing Egypt to the GLOBE Study of 62 societies. Journal of Business and Management Research, 1(2), 1-13. http://dx.doi.org/10.5430/bmr.v1n2p2

Hall, E. T. (1976). Beyond Culture. NY: Anchor Books.

Hayden, L. (2009). Human information security behaviors: Differences across geographies and cultures in a global user survey. Paper presented at the Annual Meeting of the American Association for Information Science and Technology. [Online] Available: http://www.asis.org/Conferences/AM09/open-proceedings/papers/2.xml (November 15, 2011). http://dx.doi.org/10.1002/meet.2009.145046022

Hofstede, G. and Hofstede, G. J. (2004). Cultures and Organizations: Software of the Mind. NY: McGraw-Hill.

House, R. J., Hanges, P. J., Javidan, M., Dorfman, P. W. and Gupta, V. (2004). Culture, Leadership, and Organizations, The GLOBE Study of 62 Societies. Thousand Oaks, CA: Sage Publications.

ISO/IEC 27001 (2005). Information technology - Security techniques - Information security management systems Requirements. Geneva, Switzerland: ISO. 
Kahneman, D. and Tversky, A. (1979). Prospect theory: an analysis of decision under risk. Economoetrica, 47, 263-291. http://dx.doi.org/10.2307/1914185

Lacey, D. (2009). Managing the Human Factor in Information Security: How to win over staff and influence business. West Sussex, England: Wiley.

O’Neil, D. (2006). Human culture: Understanding cultural behavior. [Online] Available: http://anthro.palomar.edu/culture/culture_3.htm (November 22, 2011).

Pronin, E. (2006). Perception and misperception of bias in human judgment. Journal of Trends in Cognitive Sciences, 11, 37-43. http://dx.doi.org/10.1016/j.tics.2006.11.001

Schneier, B. (2008). The psychology of security. [Online] Available: http://www.schneier.com/essay-155.html (November 22, 2011).

Schweitzer, J. A. (1996). Protecting Business Information. Newton, MA: Butterworth-Heinemann.

Siripukdee, S., Waluyan, L., Noguera, S. and Asai, T. (2010). Empirical analysis of human-related problems on information security in cross-cultural environment - Focusing on Japanese companies in Thailand -. Journal of Information and Management, 30(4), 96-106.

Straker, D. (2002). Trompenaars' four diversity cultures. [Online] Available: http://changingminds.org/explanations/culture/trompenaars_four_cultures.htm (October 21, 2009).

Waluyan, L., Blos, M., Noguera, S. \& Asai, T. (2010). Potential problems in people management concerning information security in cross-cultural environment - the case of Brazil. Information Processing Society of Japan Journal, 51(2), 613-623. http://dx.doi.org/10.2197/ipsjjip.18.38

Waluyan, L., Sasipan, S., Noguera, S. and Asai, T. (2009). Analyses of potential problems in people management concerning information security in cross-cultural environment - In the case of Malaysia -. Proceedings of the $3^{\text {rd }}$ International Symposium on Human Aspects of Information Security \& Assurance (HAISA 2009), 13-24.

West, R. (2008) The psychology of security. Communications of the Association for Computing Machinery, 51(4), 34-41. http://dx.doi.org/10.1145.1330311.1330320

Williams, B. R. (2011). Do it differently. Journal of Information Systems Security Association, 9(5), 3-4.

Würtz, E. (2005). A cross-cultural analysis of websites from high-context cultures and low-context cultures. Journal of Computer-Mediated Communication, 11(1).

Yates, M. (2006). Cultural differences. [Online] Available: http://www.leadervalues.com/content/details.asp?contentDetailD-255\&Type=More (December 02, 2008).

Table 1. Hofstede's cultural dimensions (Yates, 2006)

\begin{tabular}{lll}
\hline \multirow{2}{*}{ Definition } & \multicolumn{1}{c}{ High } & \multicolumn{1}{c}{ Level } \\
\cline { 2 - 3 } $\begin{array}{l}\text { PDI } \\
\text { (Power Distance } \\
\text { Index) }\end{array}$ & $\begin{array}{l}\text { The members expect that some } \\
\text { individuals wield larger amounts of } \\
\text { power than others. }\end{array}$ & $\begin{array}{l}\text { Reflects the view that all people should } \\
\text { have equal rights. }\end{array}$ \\
\hline $\begin{array}{l}\text { IDV } \\
\text { (Individualism) }\end{array}$ & Ties between individuals are loose. & Ties between individuals are tight. \\
\hline $\begin{array}{l}\text { MAS } \\
\text { (Masculinity) }\end{array}$ & $\begin{array}{l}\text { Stress on equity, competition and } \\
\text { performance. Managers are expected } \\
\text { to be decisive and assertive. }\end{array}$ & $\begin{array}{l}\text { Stress on equality, solidarity and quality } \\
\text { of work life. Managers use intuition and } \\
\text { strive for consensus. }\end{array}$ \\
\hline $\begin{array}{l}\text { UAI } \\
\text { (Uncertainty }\end{array}$ & $\begin{array}{l}\text { Many rules and low tolerance of } \\
\text { deviant ideas, resistance to change. }\end{array}$ & $\begin{array}{l}\text { Few rules and high tolerance of deviant } \\
\text { ideas. }\end{array}$ \\
\hline $\begin{array}{l}\text { LTO } \\
\text { (Long-Term }\end{array}$ & $\begin{array}{l}\text { Persistence, ordering relationships by } \\
\text { Status, thrift and having a sense of } \\
\text { shame. }\end{array}$ & $\begin{array}{l}\text { Personal steadiness and stability, } \\
\text { protecting your face, respect for } \\
\text { tradition and reciprocation of greeting, } \\
\text { favours \& gifts. }\end{array}$ \\
\hline
\end{tabular}

Hofstede's CDs, summarized by Yates (2006), are presented in Table 1. 
Table 2. Hofstede's scores classified by the degree

\begin{tabular}{|c|c|c|c|c|c|c|c|c|c|}
\hline \multirow{2}{*}{$\begin{array}{c}\text { Cultural } \\
\text { Dimension }\end{array}$} & \multirow{2}{*}{ Degree } & \multicolumn{8}{|c|}{ Country } \\
\hline & & RU & IN & $\mathrm{CN}$ & BR & TH & VN & MA & EA \\
\hline \multirow{5}{*}{ PDI } & Very low & & & & & & & & \\
\hline & Low & & & & & & & & \\
\hline & Moderate & & & & & 64 & & & 64 \\
\hline & High & & 77 & 80 & 69 & & 81 & & \\
\hline & Very high & 93 & & & & & & 104 & \\
\hline \multirow{5}{*}{ IDV } & Very low & & & 20 & & & 12 & & \\
\hline & Low & 39 & & & 38 & 20 & & 26 & 27 \\
\hline & Moderate & & 48 & & & & & & \\
\hline & High & & & & & & & & \\
\hline & Very high & & & & & & & & \\
\hline \multirow{5}{*}{ MAS } & Very low & & & & & & & & \\
\hline & Low & 36 & & & & 34 & & & \\
\hline & Moderate & & 56 & & 49 & & & 50 & 41 \\
\hline & High & & & 66 & & & 73 & & \\
\hline & Very high & & & & & & & & \\
\hline \multirow{5}{*}{ UAI } & Very low & & & & & & & & \\
\hline & Low & & 40 & 30 & & & & 36 & \\
\hline & Moderate & & & & & 64 & & & 52 \\
\hline & High & & & & 76 & & 76 & & \\
\hline & Very high & 95 & & & & & & & \\
\hline \multirow{5}{*}{ LTO } & Very low & & & & & & & & \\
\hline & Low & & & & & & & & 25 \\
\hline & Moderate & & 61 & & 65 & 56 & & & \\
\hline & High & & & & & & & & \\
\hline & Very high & & & 118 & & & & & \\
\hline
\end{tabular}

Table 2 presents Hofstede's scores for each of the investee countries in these previously conducted studies.

Table 3. Correlation matrix of Hofstede's cultural scores

\begin{tabular}{r|llllllll}
\hline & RU & IN & CN & BR & TH & VN & MA & EA \\
\hline RU & 1.00 & & & & & & & \\
IN & 0.20 & 1.00 & & & & & & \\
CN & 0.20 & 0.68 & 1.00 & & & & & \\
BR & 0.95 & 0.16 & 0.33 & 1.00 & & & & \\
TH & 0.96 & 0.31 & 0.43 & 0.99 & 1.00 & & & \\
VN & 0.61 & 0.37 & 0.70 & 0.80 & 0.82 & 1.00 & & \\
MA & 0.50 & 0.94 & 0.88 & 0.45 & 0.59 & 0.61 & 1.00 & \\
EA & 0.86 & 0.36 & -0.10 & 0.60 & 0.62 & 0.86 & 0.82 & 1.00 \\
\hline
\end{tabular}

Table 3 depicts the correlation matrix of cultural scores among each country studied. 
Table 4. Conventional wisdom about people and risk perception (Schneier, 2008)

\begin{tabular}{l|l}
\hline \multicolumn{1}{c|}{ Exaggerated risks } & \multicolumn{1}{c}{ Downplayed risks } \\
\hline Spectacular & Pedestrian \\
\hline Rare & Common \\
\hline Personified & Anonymous \\
\hline Beyond their control or externally imposed & More under their control or taken willingly \\
\hline Talked about & Not discussed \\
\hline Intentional or man-made & Natural \\
\hline Immediate & Long-term or diffuse \\
\hline Sudden & Evolving slowly over time \\
\hline Affecting them personally & Affecting others \\
\hline New and unfamiliar & Familiar \\
\hline Uncertain & Well understood \\
\hline Directed against their children & Directed towards themselves \\
\hline Morally offensive & Morally desirable \\
\hline Entirely without redeeming features & Associated with some ancillary benefit \\
\hline Not like their current situation & Like their current situation \\
\hline
\end{tabular}

Reasons for incorrect perception of risks are listed in Table 4.

Table 5. Profile of respondents

\begin{tabular}{|c|c|c|c|c|c|c|c|c|c|}
\hline Investee Country & $\begin{array}{c}\text { MY } \\
\mathrm{S}\end{array}$ & THA & VEN & $\mathrm{EAC}$ & BRA & IND & $\mathrm{CHN}$ & RUS & Total \\
\hline \multicolumn{10}{|l|}{ Gender } \\
\hline Male & 80 & 91 & 34 & Not asked & 46 & 113 & 102 & 97 & 563 \\
\hline Female & 60 & 164 & 25 & Not asked & 15 & 36 & 84 & 43 & 427 \\
\hline Not Answered & - & - & - & 30 & - & 2 & - & 12 & 44 \\
\hline \multicolumn{10}{|l|}{ Age } \\
\hline 19 or under & 0 & 4 & 0 & & 0 & 8 & 0 & 1 & 13 \\
\hline $20-29$ & 69 & 165 & 25 & & 33 & 103 & 74 & 65 & 534 \\
\hline $30-39$ & 58 & 70 & 12 & Not & 16 & 25 & 88 & 72 & 341 \\
\hline $40-49$ & 10 & 13 & 14 & Asked & 9 & 11 & 19 & 12 & 88 \\
\hline $50-59$ & 3 & 3 & 8 & & 3 & 3 & 5 & 2 & 27 \\
\hline 60 or older & 0 & 0 & 0 & & 0 & 1 & 0 & 0 & 1 \\
\hline Not Answered & & & & & & & & & 30 \\
\hline \multicolumn{10}{|l|}{$\begin{array}{l}\text { Investor } \\
\text { Countries }\end{array}$} \\
\hline $\mathrm{JP}$ & 27 & 81 & 44 & $\sqrt{ }$ & 20 & 30 & 32 & 25 & 259 \\
\hline US & 38 & 66 & 15 & $\sqrt{ }$ & 20 & 39 & 30 & 35 & 243 \\
\hline UK & 21 & 34 & - & $\sqrt{ }$ & - & 30 & 30 & 34 & 149 \\
\hline $\mathrm{SG}$ & 40 & 17 & - & - & - & 30 & 31 & - & 118 \\
\hline NL & - & - & - & - & 21 & 22 & - & 23 & 66 \\
\hline $\mathrm{DE}$ & 14 & 15 & - & - & - & - & - & 35 & 64 \\
\hline $\mathrm{HK}$ & - & 9 & - & - & - & - & - & - & 9 \\
\hline $\mathrm{TW}$ & - & 4 & - & - & - & - & 30 & - & 30 \\
\hline $\mathrm{KR}$ & - & - & - & - & - & - & 33 & - & 33 \\
\hline Other & - & 29 & - & $\sqrt{ }$ & - & - & - & - & 29 \\
\hline $\begin{array}{l}\text { Total } \\
\text { Respondents }\end{array}$ & 140 & 255 & 59 & 30 & 61 & 151 & 186 & 152 & 1034 \\
\hline
\end{tabular}

The overall profile of respondents (Asai, 2011 , and Asai, 2011 $1_{\mathrm{b}}$ ) is summarized in Table 5. 
Table 6. Serious problems in investee countries

\begin{tabular}{|c|c|c|c|c|c|c|c|c|c|}
\hline \multirow{2}{*}{$C D$} & \multirow{2}{*}{ Problem } & \multicolumn{4}{|c|}{ Country } & \multirow[b]{2}{*}{$\mathrm{TH}$} & \multirow[b]{2}{*}{$\mathrm{VN}$} & \multirow[b]{2}{*}{ MA } & \multirow[b]{2}{*}{ EA } \\
\hline & & RU & IN & $\mathrm{CN}$ & BR & & & & \\
\hline \multirow{2}{*}{ PDI } & Lack of education about company's ISM & - & $\sqrt{ }$ & - & - & - & - & - & - \\
\hline & Not giving opinions to managers concerning ISM & - & - & - & - & - & - & - & $\sqrt{ }$ \\
\hline \multirow{3}{*}{ IDV } & Unintentional sharing of confidential information & $\sqrt{ }$ & $\sqrt{ }$ & $\sqrt{ }$ & $\sqrt{ }$ & $\sqrt{ }$ & - & $\sqrt{ }$ & $\sqrt{ }$ \\
\hline & Concealing faults made by friends & $\sqrt{ }$ & $\sqrt{ }$ & $\sqrt{ }$ & - & $\sqrt{ }$ & - & - & - \\
\hline & $\begin{array}{l}\text { Placing lower priority to rules rather than to } \\
\text { friendship or feelings }\end{array}$ & - & - & - & - & - & $\sqrt{ }$ & - & - \\
\hline \multirow[t]{2}{*}{ MAS } & $\begin{array}{l}\text { Using any means to reach goals owing to high } \\
\text { competition }\end{array}$ & - & $\sqrt{ }$ & $\sqrt{ }$ & $\sqrt{ }$ & - & $\sqrt{ }$ & $\sqrt{ }$ & $\sqrt{ }$ \\
\hline & Disgruntled employees & - & - & - & - & - & - & $\sqrt{ }$ & - \\
\hline \multirow{5}{*}{ UAI } & $\begin{array}{l}\text { Unwilling to follow information security policy } \\
\text { without complete understanding }\end{array}$ & $\sqrt{ }$ & - & - & - & - & - & - & - \\
\hline & Less interest in ISM & - & $\sqrt{ }$ & - & - & - & - & - & - \\
\hline & Lower priority to ISM/Information Security Policy & - & - & $\sqrt{ }$ & - & $\sqrt{ }$ & - & - & $\sqrt{ }$ \\
\hline & Lack of interest in ISM & - & - & - & - & $\sqrt{ }$ & - & - & - \\
\hline & Lack of interest in information outside duties & - & - & - & - & $\sqrt{ }$ & - & - & - \\
\hline \multirow{2}{*}{ LTO } & Using previous company's confidential information & - & $\overline{\sqrt{ }}$ & $\overline{\sqrt{ }}$ & $\sqrt{ }$ & $\sqrt{ }$ & - & - & $\overline{\sqrt{ }}$ \\
\hline & Less response to information transferred by e-mail & - & - & - & - & - & - & $\sqrt{ }$ & - \\
\hline
\end{tabular}

Table 6 lists the common problems found to be serious in each of these countries and the CDs under which they are categorized. 


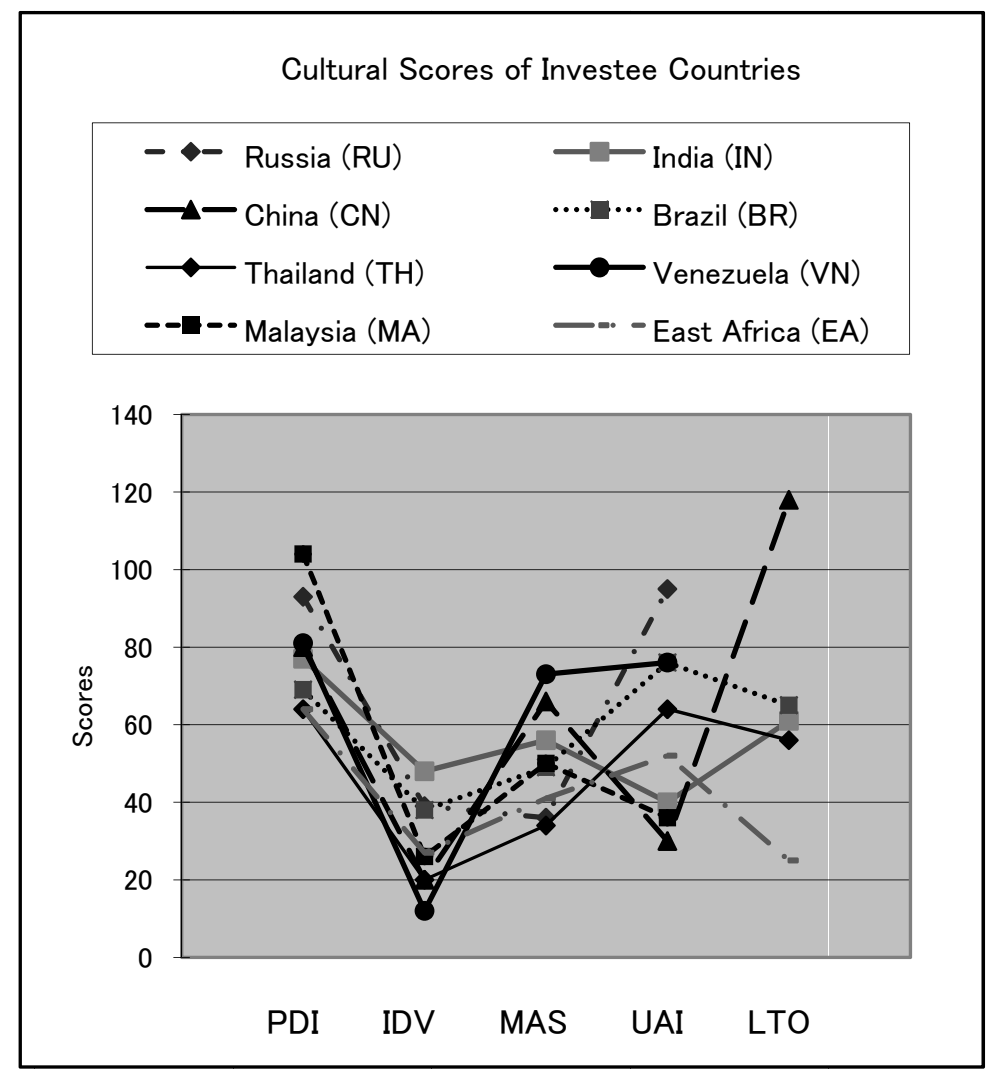

Figure 1. Hofstede's cultural scores for investee countries

Figure 1 represents Hofstede's cultural scores for examined countries graphically.

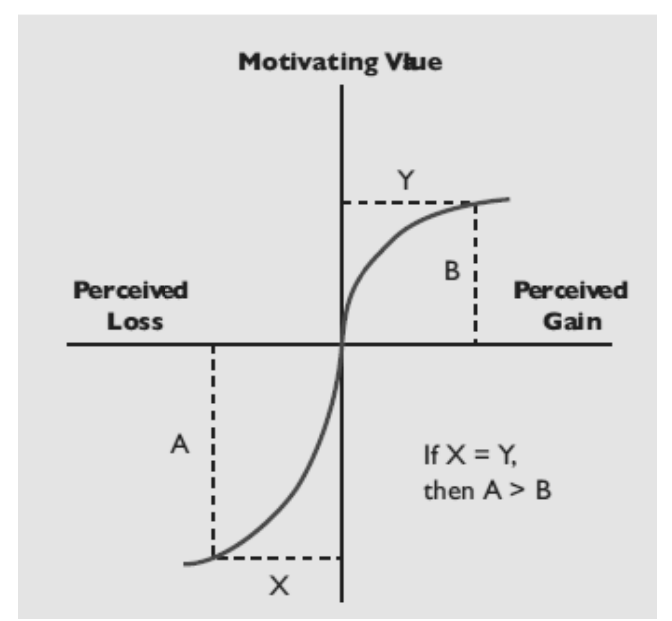

Figure 2. Losses carry more weight compared to gains (West, 2008)

Figure 2 shows that humans value something more when it is represented as something that can be lost, as opposed to a potential gain. 